\title{
Astigmatism in 12-Year-Old Australian Children: Comparisons with a 6-Year-Old Population
}

\author{
Son C. Huynb, ${ }^{1}$ Annette Kifley, ${ }^{1}$ Katbryn A. Rose, ${ }^{2}$ Ian G. Morgan, ${ }^{3,4}$ and Paul Mitchell ${ }^{1,5}$
}

Purpose. To study the distributions of refractive (RA), corneal (CA), and internal astigmatism (IA) in 12-year-old Australian children and to explore differences from previous findings in 6-year-old children.

Methods. Eligible year 7 students (2353/3144 [75.3\%], median age, 12 years) from a random cluster sample of 21 high schools in Sydney, Australia, were examined by keratometry, cycloplegic autorefraction, and review of questionnaire data.

REsults. Prevalence rates of RA, CA, and IA $\geq 1.0 \mathrm{D}$ in right eyes were $6.7 \%$ (95\% confidence interval [CI], 5.0-8.4), 26.6\% (CI, 22.1-31.1), and 26.5\% (CI, 22.9-30.0), respectively. RA was predominantly with-the-rule (WTR; $40.4 \%, \mathrm{CI}, 32.6$ to 48.2 ) and against-the-rule (ATR; 43.6\%, CI, 35.7-51.5), CA was WTR (88.8\%, CI, 86.3-91.3), and IA was ATR (90.2\%, CI, 87.8-92.6). The girls had significantly greater CA and IA prevalence, with greater ATR astigmatism and lower oblique IA than did the boys. The European white-Australian children had lower CA prevalence than did the East Asian-Australian children and higher IA prevalence than did the South Asian-Australian children. Ethnic differences in RA prevalence were not significant, when adjusted for confounders. RA was more frequently ATR in European white than in other ethnic groups. Compensation between CA and IA reduced the magnitude of RA. Comparison with the data on 6-year-old children revealed minimal differences for all astigmatic components.

Conclusions. There was a relatively low prevalence of RA, due to compensation between CA and IA. The minimal differences in all components of astigmatism between the two age cohorts suggest that astigmatism is stable between ages 6 and 12 years, although this conclusion needs to be confirmed in longitudinal studies. (Invest Ophthalmol Vis Sci. 2007;48:73-82) DOI: 10.1167/iovs.06-0263

A stigmatism is an important condition because it is a freAquent, correctable cause of visual impairment in children, whether or not this coexists with spherical errors. ${ }^{1}$ Although

From the ${ }^{1}$ Centre for Vision Research, Department of Ophthalmology and Westmead Millennium Institute, University of Sydney, and the ${ }^{5}$ Vision Co-operative Research Centre, University of New South Wales, Sydney, Australia; the ${ }^{2}$ School of Applied Vision Sciences, Faculty of Health Sciences, University of Sydney, Sydney, Australia; and the ${ }^{3}$ ARC Centre of Excellence in Vision Science and ${ }^{4}$ Research School of Biological Sciences, Australian National University, Canberra, Australia.

Supported by the Australian National Health and Medical Research Council, Canberra (Grant 253732) and the Vision Co-operative Research Centre, University of New South Wales, Sydney, Australia.

Submitted for publication March 12, 2006; revised July 10, August 8, and September 14, 2006; accepted November 15, 2006.

Disclosure: S.C. Huynh, None; A. Kifley, None; K. Rose, None; I. Morgan, None; P. Mitchell, None

The publication costs of this article were defrayed in part by page charge payment. This article must therefore be marked "advertisement" in accordance with 18 U.S.C. $\$ 1734$ solely to indicate this fact.

Corresponding author: Paul Mitchell, Centre for Vision Research, Department of Ophthalmology, University of Sydney, Hawkesbury Road, Westmead, NSW 2145, Australia;

paul_mitchell@wmi.usyd.edu.au. there have been population-based reports on the prevalence of astigmatism in older children from different ethnic groups, ${ }^{2-5}$ these focused exclusively on refractive astigmatism, and data on the distribution of corneal and internal (or lenticular) astigmatism remain limited. ${ }^{6-8}$ To improve our understanding of this condition, it is important to know the distribution of all the components of astigmatism, their association with each other, age-related changes, and factors that influence the compensation between corneal and internal astigmatism.

In a recent paper on a large cohort of predominantly 6-yearold Australian children, ${ }^{9}$ we reported the distribution of the components of astigmatism, their variation with gender and ethnic background, and the influence of spherical equivalent refraction. Compensation between corneal and internal astigmatic components, which reduces the magnitude of refractive astigmatism, was also demonstrated. Further knowledge of similar issues in older children will help to improve our understanding of this condition.

Therefore, in this study we sought to (1) report the distribution of refractive, corneal, and internal astigmatism and how these parameters vary with gender, ethnic background, and spherical equivalent refraction in 12-year-old children, (2) document the effectiveness of compensation of corneal astigmatism at this age, and (3) compare the findings in this 12-year-old sample with previously reported cross-sectional data on 6-yearold children.?

\section{Methods}

\section{Subjects}

The Sydney Myopia Study is a population-based survey of eye conditions in school children living within the Sydney Metropolitan Area, Australia. It was approved by the Human Research Ethics Committee, University of Sydney, the Department of Education and Training, and Catholic Education Office, New South Wales, Australia. The project forms part of the broader Sydney Childhood Eye Study. Conduct of the study was in accordance with tenets of the Declaration of Helsinki. We obtained informed written consent from at least one parent of each child, as well as verbal assent from every child before the examinations.

Study methods were previously described for year-1 students (mean age, 6.7 years, hereafter referred to as the 6-year-old cohort). ${ }^{9,10}$ Similar methods were used for the current cohort of older children, including use of the same instruments. Briefly, all year 7 students (median age, 12 years, hereafter referred to as the 12-year-old cohort) in a stratified random cluster sample of 21 Sydney high schools were eligible to participate. Stratification was based on socioeconomic status data from the Australian Bureau of Statistics (2001 national census). This included a proportional mix of public and private or religious high schools. Examinations were conducted during 2004 and 2005. Data for the 6-year-old cohort were collected during 2003 and 2004 and for the 12-year-old cohort during 2004 and 2005. As a result, there was no overlap in the samples, and children who were examined as part of the 6-year-old cohort were not, and could not have been, re-examined as part of the 12-year-old cohort. 


\section{Keratometry and Cycloplegic Autorefraction}

Keratometry was performed before cycloplegia (IOLMaster; Carl Zeiss, Jena, Germany). A corneal refractive index of 1.3375 was assumed in calculations of corneal power to take into account the negative refractive power of the posterior corneal surface. Each reading was the average of five internal measurements. Only readings with all six measurement mires in focus were accepted. We made sequential readings until three were obtained in which corneal astigmatism varied by $<0.1 \mathrm{D}$, and axis varied by less than $5^{\circ}$ for astigmatism $\geq 0.5 \mathrm{D}$ and less than $10^{\circ}$ for astigmatism $<0.5 \mathrm{D}$. The last of these three readings was used in the analyses.

After instillation of $1 \%$ amethocaine (1 drop) to obtain corneal anesthesia, cycloplegia was induced by instilling $1 \%$ cyclopentolate ( 1 drop) 2 minutes later. For children with inadequate mydriasis $(<6$ $\mathrm{mm}$ ), further instillations included $1 \%$ tropicamide and/or $2.5 \%$ phenylephrine (1 drop each). Autorefraction was performed 25 to 30 minutes after the last drop (RK-F1 Autorefkeratometer; Canon, Tokyo, Japan). In fully automated mode, at least 5 autorefractions were performed, and a standardized value was obtained.

\section{Questionnaire Data}

Questionnaires completed by the parents were used to obtain information on socioeconomic status, level of education achieved, and ethnic background of the child. Ethnic groups represented in the city of Sydney, on which data are presented in this article, include European white, East Asian, South Asian (Indian, Pakistani, Sri Lankan) and Middle Eastern. Ethnic groups on which data are not presented due to their small numbers included African, Pacific Islander (Melanesian, Polynesian), Indigenous Australian, and South American. Socioeconomic status was determined from parental employment and home ownership.

\section{Definitions}

All components of astigmatism were expressed as the negative correcting cylinder. Corneal astigmatism was calculated as the refractive power difference between the flattest and steepest meridians, while the axis was set along the flattest meridian. Refractive and corneal cylinders $(C)$, together with their axes $(\theta)$, were converted into vectors for further analysis. ${ }^{11}$ The $J_{0}$ vector, given by $(-C \times \cos 2 \theta) / 2$, represents a Jackson cross-cylinder (JCC) with axes at $180^{\circ}$ and $90^{\circ}$. With(WTR) and against (ATR)-the-rule axes are represented by positive and negative $J_{0}$, respectively. The $J_{45}$ vector, given by $(-\mathrm{C} / 2 \times \sin 2 \theta) / 2$, describes a JCC in which power is greatest at either $135^{\circ}\left(+J_{45}\right)$ or $45^{\circ}$ $\left(-J_{45}\right)$. The conventional approach was also used to describe WTR $\left(1-15^{\circ}\right.$ or $\left.165-180^{\circ}\right)$ and ATR $\left(75-105^{\circ}\right)$ axes. All other axis orientations were described as oblique. Internal astigmatism was calculated as the vector difference between refractive and corneal components. ${ }^{12}$

Astigmatism was defined for cylinder powers $\geq 0.50, \geq 0.75, \geq 1.00$, and $\geq 1.50 \mathrm{D}$. Spherical equivalent (SEq) was calculated as sphere $+1 / 2$ cylinder.

\section{Statistical Analysis}

Analyses were performed on data for right eyes (Statistical Analysis System software ver. 9.1; SAS Institute, Cary, NC). We adjusted for the potential effects of cluster sampling, in which data between children attending the same school were correlated, by using generalized estimating equations to estimate prevalence and mixed models to estimate means.

Effects of gender, ethnic background and spherical equivalent were examined in unadjusted and multivariate-adjusted analyses. The relationship between corneal and refractive astigmatism was assessed with mixed models linear regression.
Table 1. Characteristics of Participating Children and Their Parents

\begin{tabular}{lc}
\hline \multicolumn{1}{c}{ Characteristic } & $\boldsymbol{n}(\%)$ \\
\hline Age (years) & \\
11 to $<12$ & $100(4.3)$ \\
12 to $<13$ & $1645(69.9)$ \\
13 to $<14$ & $603(25.6)$ \\
$14+$ & $5(0.2)$ \\
Gender (boys) & $1190(50.6)$ \\
Ethnic background & \\
European white & $1407(60.0)$ \\
East Asian & $352(15.0)$ \\
Middle Eastern & $166(7.1)$ \\
South Asian & $129(5.5)$ \\
Other ethnic groups* & $291(12.4)$ \\
Parental education & $684(33.3)$ \\
Secondary school & $536(26.1)$ \\
Technical college & $834(40.6)$ \\
University & \\
Parental employment & $1183(57.0)$ \\
Both employed & $695(33.5)$ \\
One employed & $198(9.5)$ \\
Unemployed & $1555(74.2)$ \\
Home ownership (owns home)
\end{tabular}

$n=2353$

* Comprised children of Pacific Islander (3.3\%), South American $(0.9 \%)$, African (0.3\%), Indigenous Australian (0.3\%), and mixed and other ethnic backgrounds (7.6\%)

\section{Results}

\section{Characteristics of the Study Population}

Among 3144 eligible children, 2367 (75.3\%) participated in the study, although 14 with completed parental questionnaires were not examined due to absence from school, leaving data available for 2353 children. The mean age of children examined was 12.7 years (range, $11.1-14.4) ; 50.6 \%$ were boys. Mean spherical equivalent was $+0.48 \mathrm{D}$ (range, -10.87 to $+8.37 \mathrm{D}$ ). Prevalence rates for myopia (SEq $\leq-0.5 \mathrm{D})$ and moderate hyperopia (SEq $\geq+2.0 \mathrm{D}$ ) were $12.8 \%$ (95\% confidence interval $[\mathrm{CI}], 7.2-18.4)$ and $5.0 \%$ (CI, 4.1-5.8), respectively. The ethnic composition of participating children, parental education level, employment status, and home ownership are presented in Table 1 . The gender and ethnic composition of nonparticipating children, informally assessed, was similar to that of children who participated.

\section{Overall Distribution in the 12-Year-Old Cohort}

Prevalence of Astigmatism. The distributions of refractive, corneal, and internal astigmatism are shown in Figures 1A, $1 \mathrm{~B}$, and 1C, respectively. Previous results for the 6-year-old cohort are also shown for comparison and were very similar. Refractive astigmatism followed a distribution in which there were high frequencies of low astigmatism and very low frequencies of high astigmatism. The distributions of both corneal and internal astigmatism showed peaks in the range 0.5 to $<1.0 \mathrm{D}$.

The prevalence rates of refractive, corneal, and internal astigmatism $\geq 0.75, \geq 1.0$, and $\geq 1.5 \mathrm{D}$ are presented in Table 2 . Refractive astigmatism of $\geq 0.5$ and $\geq 2.0 \mathrm{D}$ was found in $28.9 \%$ (CI, 25.8-31.9) and $1.4 \%$ (CI, 0.7-2.1) of children, respectively. Corresponding rates for corneal astigmatism were $69.5 \%$ (CI, 64.8-74.3) and 2.6\% (CI, 1.3-3.9) and for internal astigmatism, 78.3\% (CI, 75.5-81.1) and 0.3\% (CI, 0.1-0.5).

Axis of Astigmatism. The proportions of children with different types of axis of astigmatism varied with the level of astigmatism. For astigmatism of any magnitude, the percent- 

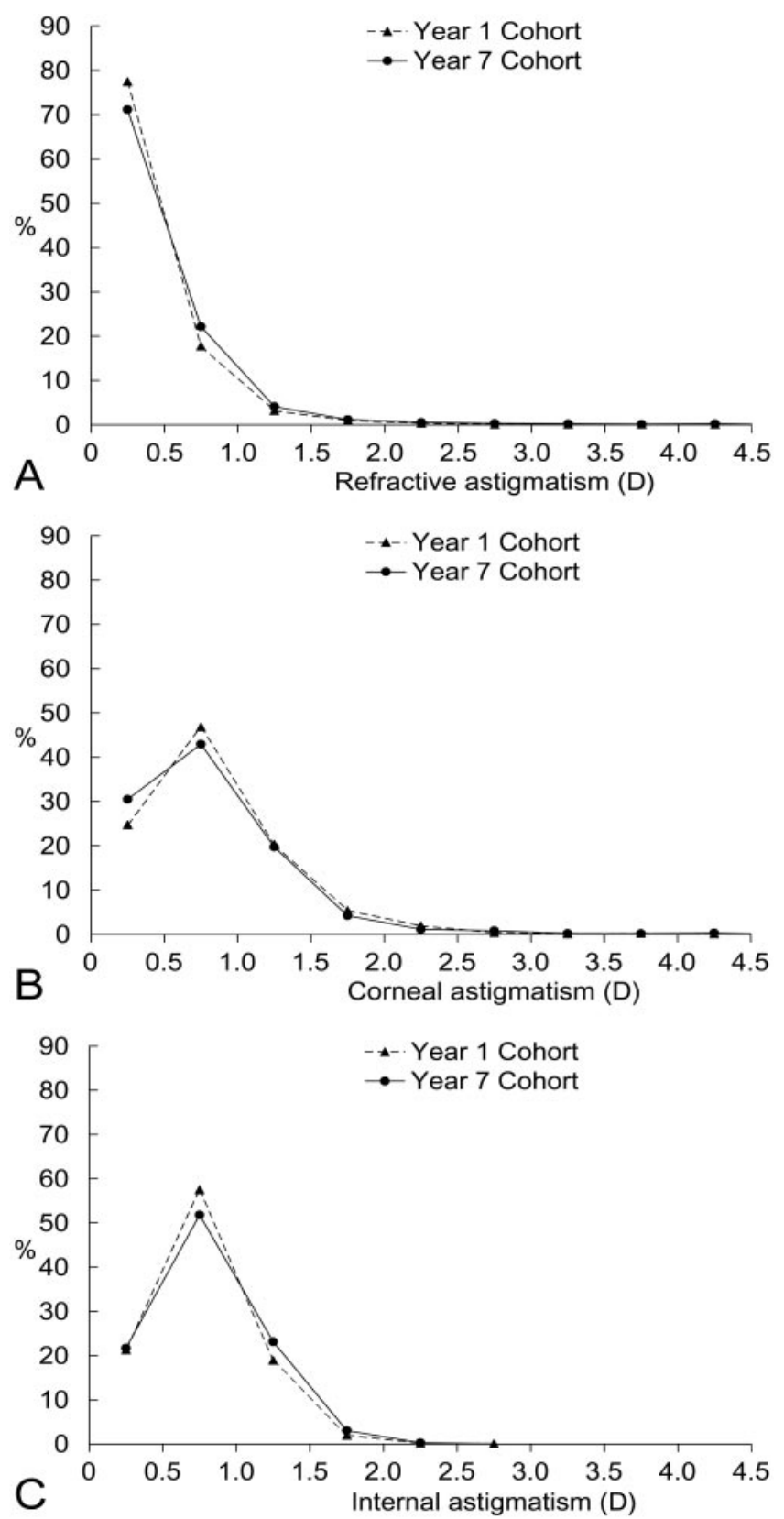

FigURE 1. Comparative distributions of the overall prevalence in right eyes of (A) refractive, (B) corneal, and (C) internal astigmatism between the cohorts of year $1^{9}(n=1740)$ and year $7(n=2353)$ students.

ages of WTR, ATR, and oblique refractive astigmatism were 22.1\% (CI, 20.0-24.2), 42.4\% (CI, 39.9-44.9), and 35.5\% (CI, 33.1-37.9), respectively (Fig. 2). Corresponding percentages for the axis of corneal astigmatism were $69.2 \%$ (CI, 67.2-71.1), 4.1\% (CI, 3.3-4.9), and 26.8\% (CI, 24.9-28.6), whereas for internal astigmatism they were $0.9 \%$ (CI, 0.5-1.3), $76.0 \%$ (CI, 74.3-77.8), and $23.1 \%$ (CI, 21.4-24.8). Previous results for the 6-year-old cohort are also shown for comparison.

The distributions of axis of astigmatism $\geq 1 \mathrm{D}$ are shown in Table 3. There were similar proportions of children with WTR (40.4\%) and ATR (43.6\%) refractive astigmatism. Corneal astigmatism was mainly WTR $(88.8 \%)$, whereas only $1.3 \%$ of children had an ATR axis. Internal astigmatism was composed entirely of ATR (90.2\%) and oblique (9.8\%) axes.

\section{Gender Differences in Astigmatism}

Prevalence of Astigmatism. Gender-specific prevalence rates of the components of astigmatism $(\geq 0.75, \geq 1.0$, and $\geq 1.5 \mathrm{D}$ ) are shown in Table 2 . After adjustment for age, ethnic background, socioeconomic status, parental education, spherical equivalent, and effects of cluster sampling, there were no significant gender differences in the prevalence of refractive astigmatism. Corneal and internal astigmatism, however, were significantly more prevalent in girls, except for internal astigmatism $\geq 1.5 \mathrm{D}$.

Axis of Astigmatism. Gender-specific distributions of the axes of astigmatism $\geq 1 \mathrm{D}$ are shown in Table 3 . After adjustment for age, ethnic background, socioeconomic status, parental education, spherical equivalent, and effects of cluster sampling, there were no significant gender differences in refractive and corneal axes, although the girls had a significantly higher percentage of WTR but a lower percentage of oblique internal astigmatism. Considering astigmatism of any magnitude, the finding was similar for axis of refractive astigmatism, but corneal astigmatism was more frequently WTR and less frequently ATR and oblique in the girls (all $P<0.002$ ), although these differences were small. Internal astigmatism was more frequently ATR but less frequently oblique (both $P=0.02$ ).

\section{Ethnic Differences in Astigmatism}

Prevalence of Astigmatism. The children of East Asian background had higher prevalence rates of refractive $(\geq 1.0$, $\geq 1.5 \mathrm{D})$ and corneal ( $\geq 0.75, \geq 1.0, \geq 1.5 \mathrm{D})$ astigmatism than did those of European white background (Table 2). These differences were statistically significant after adjustment for cluster sampling, but only differences in corneal astigmatism remained significant after adjustment for age, gender, socioeconomic status, parental education, spherical equivalent, and cluster sampling. There were no significant differences in internal astigmatism between the children of East Asian and European white backgrounds.

The children of South Asian background had a significantly higher prevalence of refractive $(\geq 0.75, \geq 1.0 \mathrm{D})$ and corneal astigmatism ( $\geq 0.75, \geq 1.5 \mathrm{D})$, but a lower prevalence of internal astigmatism $(\geq 0.75, \geq 1.0 \mathrm{D})$ than did those of European white background, after adjustment for the effects of cluster sampling. Only differences in corneal and internal astigmatism remained significant after adjustment for the other variables.

The prevalence of refractive $(\geq 1.5 \mathrm{D})$ and corneal $(\geq 1.5 \mathrm{D})$ astigmatism was significantly higher, and the prevalence of internal astigmatism ( $\geq 0.75,1.0 \mathrm{D})$ was significantly lower in the children of Middle Eastern than in those of European white background after adjustment for cluster sampling. These differences remained statistically significant, except for internal astigmatism $\geq 0.75 \mathrm{D}$, after adjustment for the other variables.

Axis of Astigmatism. Ethnic differences in axis were found only for refractive astigmatism ( $\geq 1 \mathrm{D}$; Table 3 ). These included markedly higher proportions of WTR and markedly lower proportions of ATR axis in all the children of nonEuropean white background. These differences remained statistically significant after adjustment for multiple variables. There were no ethnic differences in oblique refractive astigmatism or in the axes of corneal and internal astigmatism. Similar ethnic differences in axis were generally found when astigmatism of any magnitude was considered. However, the children of East Asian background had significantly higher proportions of oblique refractive $(P=0.003)$ and WTR corneal $(P<0.0001)$ axes, and lower proportions of ATR $(P=0.0005)$ and oblique $(P<0.0001)$ corneal axes. There were no differences in axis of internal astigmatism between the children of East Asian and European white backgrounds. The children of South Asian background had a significantly higher proportion 
TABLE 2. Prevalence (\%) of the Components of Astigmatism in Right Eyes by Different Definitions with Stratification by Gender and Ethnic Background

\begin{tabular}{|c|c|c|c|c|c|c|c|}
\hline \multirow[b]{2}{*}{ Astigmatism Type } & \multirow[b]{2}{*}{$n(\%)$} & \multicolumn{2}{|c|}{$\geq 0.75 \mathrm{D}$} & \multicolumn{2}{|c|}{$\geq 1.0 \mathrm{D}$} & \multicolumn{2}{|c|}{$\geq 1.5 \mathrm{D}$} \\
\hline & & $\%(95 \% \mathrm{CI})$ & $\boldsymbol{P}^{*}$ & $\%(95 \%$ CI) & $\boldsymbol{P}^{*}$ & $\%(95 \%$ CI) & $P^{*}$ \\
\hline \multicolumn{8}{|l|}{ Refractive } \\
\hline All & $2336(100)$ & $13.6(11.2-16.0)$ & & $6.7(5.0-8.4)$ & & $2.6(1.6-3.5)$ & \\
\hline Boys & $1185(50.7)$ & $13.2(10.7-15.6)$ & Referent & $6.6(4.8-8.4)$ & Referent & $2.4(1.4-3.5)$ & Referent \\
\hline Girls & $1151(49.3)$ & $14.0(10.6-17.4)$ & 0.5 & $6.8(4.7-8.9)$ & 0.7 & $2.7(1.4-3.9)$ & 0.8 \\
\hline European white & $1400(60.1)$ & $13.3(10.7-15.9)$ & Referent & $5.6(4.6-6.7)$ & Referent & $1.7(1.0-2.5)$ & Referent \\
\hline East Asian & $349(15.0)$ & $18.9(11.2-26.7)$ & 0.1 & $11.2(5.4-16.9)$ & $0.007 t$ & $4.9(1.5-8.2)$ & $0.004 \dagger$ \\
\hline Middle Eastern & $162(7.0)$ & $13.0(7.4-18.5)$ & 0.8 & $6.8(4.6-9.0)$ & 0.2 & $3.7(1.9-5.5)$ & 0.009 \\
\hline South Asian $\neq$ & $127(5.5)$ & $15.0(8.5-21.4)$ & $>0.9$ & $11.8(3.8-19.9)$ & $0.047 \dagger$ & $6.3(1.1-11.5)$ & $0.01 \dagger$ \\
\hline \multicolumn{8}{|l|}{ Corneal } \\
\hline All & $2323(100)$ & $44.8(39.4-50.1)$ & & $26.6(22.1-31.1)$ & & $6.8(4.5-9.1)$ & \\
\hline Boys & $1180(50.8)$ & $39.8(33.4-46.3)$ & Referent & $22.3(17.4-27.2)$ & Referent & $5.7(3.9-7.5)$ & Referent \\
\hline Girls & 1143 (49.2) & $49.9(44.9-54.8)$ & 0.0006 & $31.0(26.5-35.4)$ & $<0.0001$ & $8.0(4.9-11.2)$ & 0.04 \\
\hline European white & $1383(59.7)$ & $36.3(31.8-40.8)$ & Referent & $19.2(16.0-22.3)$ & Referent & $3.4(2.5-4.3)$ & Referent \\
\hline East Asian & $350(15.1)$ & $70.0(65.3-74.7)$ & $<0.0001$ & $50.0(44.3-55.7)$ & $<0.0001$ & $17.7(11.8-23.6)$ & $<0.0001$ \\
\hline Middle Eastern & $164(7.1)$ & $42.7(29.3-56.1)$ & 0.5 & $21.3(13.9-28.8)$ & 0.8 & $6.7(4.4-9.0)$ & 0.002 \\
\hline South Asian $\neq$ & $129(5.6)$ & $49.6(41.4-57.8)$ & 0.007 & $26.4(18.0-34.7)$ & 0.1 & $10.9(5.8-16.0)$ & $<0.0001$ \\
\hline \multicolumn{8}{|l|}{ Internal } \\
\hline All & $2312(100)$ & $51.9(48.4-55.5)$ & & $26.5(22.9-30.0)$ & & $3.3(2.6-4.1)$ & \\
\hline Boys & $1176(50.9)$ & $48.1(43.4-52.9)$ & Referent & $23.2(18.8-27.6)$ & Referent & $2.7(1.8-3.6)$ & Referent \\
\hline Girls & $1136(49.1)$ & $55.9(52.7-59.1)$ & 0.0008 & $29.4(26.2-33.4)$ & 0.0007 & $4.0(2.7-5.2)$ & $0.08 \S$ \\
\hline European white & $1380(59.9)$ & $52.9(47.7-58.1)$ & Referent & $27.4(22.3-32.6)$ & Referent & $3.7(2.6-4.8)$ & Referent \\
\hline East Asian & $347(15.1)$ & $56.5(52.7-60.3)$ & 0.5 & $28.8(23.9-33.8)$ & 0.8 & $4.6(2.6-6.6)$ & $0.3 \S$ \\
\hline Middle Eastern & $161(7.0)$ & $43.5(35.5-51.4)$ & $0.01 \|$ & $16.8(10.2-23.3)$ & 0.004 & $0.6(0.0-2.0)$ & $0.1 \rrbracket$ \\
\hline South Asian $\ddagger$ & $127(5.5)$ & $37.8(28.8-46.7)$ & $<0.0001$ & $13.4(7.9-18.9)$ & $<0.0001$ & $1.6(0.0-3.4)$ & $0.1 \S$ \\
\hline
\end{tabular}

* Adjusted for cluster sampling. Unless indicated, statistical significances were unchanged after adjustment for age, gender, ethnic background, socioeconomic status, parental education, spherical equivalent, and cluster sampling.

† Nonsignificant after adjustment for age, gender, socioeconomic status, parental education, spherical equivalent, and cluster sampling.

‡ Comprised children of Indian, Pakistani, and Sri Lankan backgrounds.

$\S$ These results were not adjusted for other variables due to the small sample.

$\| P=0.06$ after adjustment for age, gender, socioeconomic status, parental education, spherical equivalent, and cluster sampling.

of WTR $(P=0.005)$ and oblique $(P=0.03)$ axis and lower proportion of ATR $(P=0.005)$ axis of internal astigmatism. The proportions of ATR $(P=0.03)$ and oblique $(P=0.02)$ internal astigmatism were significantly lower in the children of Middle Eastern than in those of European white background.

\section{Effects of Spherical Equivalent}

Variations in prevalence of the components of astigmatism $(\geq 1$ D) with spherical equivalent (SEq) refraction are presented in Figure 3. Prevalence rates of refractive (Fig. 3A) and corneal (Fig. 3B) astigmatism were lowest in children with low hyperopia (SEq +0.51 to $+2.0 \mathrm{D}$ ) and increased in those with more hyperopic (SEq $>+2.0 \mathrm{D})$, emmetropic (SEq -0.5 to $+0.5 \mathrm{D})$, and myopic (SEq $\leq-0.5 \mathrm{D})$ refractions. The prevalence of internal astigmatism was markedly higher in the moderate hyperopia ( $\mathrm{SEq} \geq+2.0 \mathrm{D}$ ) group than in all other refractive categories (Fig. 3C). All these differences with the emmetropic reference group were statistically significant (all $P<0.01$ ) after adjustment for effects of cluster sampling and remained so after further adjustment for age, gender, ethnic background, socioeconomic status, and parental education, except for the prevalence of corneal astigmatism in the myopic group.

\section{Relationship between Refractive and Corneal Astigmatism}

The relationship between refractive and corneal $J_{0}$ and $J_{45}$ vectors is shown in Figures $4 \mathrm{~A}$ and $4 \mathrm{~B}$. The mean (SD) refractive $J_{0}$ was $-0.03(0.26) \mathrm{D}$, whereas the mean corneal $J_{0}$ was $0.33(0.30)$ D. Almost all points lay below the unity line, indicating that refractive $J_{0}$ tended to be less than corneal $J_{0}$. The mean refractive $J_{45}$ was $-0.03(0.12) \mathrm{D}$, whereas the mean corneal $J_{45}$ was $0.02(0.17)$ D. Data points clustered between -0.5 and +0.25 for refractive $J_{45}$ and between -0.5 and +0.5 for corneal $J_{45}$.

The overall regression slope of refractive versus corneal $J_{0}$ vector was 0.65 (CI, $0.60-0.70)$, and of $J_{45}$ vector was 0.40 (CI, $0.30-0.51$ ). There was no significant effect of gender (adjusted for ethnic background, spherical equivalent and cluster sampling) or ethnic background (adjusted for gender, spherical equivalent, and cluster sampling) on the slope of this relationship for both $J_{0}$ and $J_{45}$ vectors (all $P>0.1$ ). The slopes varied significantly, however, with spherical equivalent refraction. It was lowest in the low hyperopia group for both $J_{0}$ and $J_{45}$ vectors, and increased significantly (all $P<0.0007)$ with more hyperopic $\left(J_{0}\right.$ and $\left.J_{45}\right)$, emmetropic $\left(J_{0}\right)$, and myopic $\left(J_{0}\right.$ and $J_{45}$ ) refractions (Table 4 ).

\section{Discussion}

\section{Compensation of Astigmatism}

Consistent findings between the current cross-sectional study of predominantly 12-year-old Australian children and our previous cross-sectional study of predominantly 6-year-old children $^{9}$ are the relatively low prevalence $(6.7 \%$ and $4.8 \%$, respectively) and highly skewed distribution (Fig. 1A) of refractive astigmatism. High rates of internal (or lenticular) astigmatism appear to compensate for the high levels of corneal astigmatism, due to the approximately perpendicular orientation of their axes. Evidence of this compensation of astigmatism was also found in the relationship between the corneal and refractive $J_{0}$ and $J_{45}$ vectors. Less effective compensation is indicated 

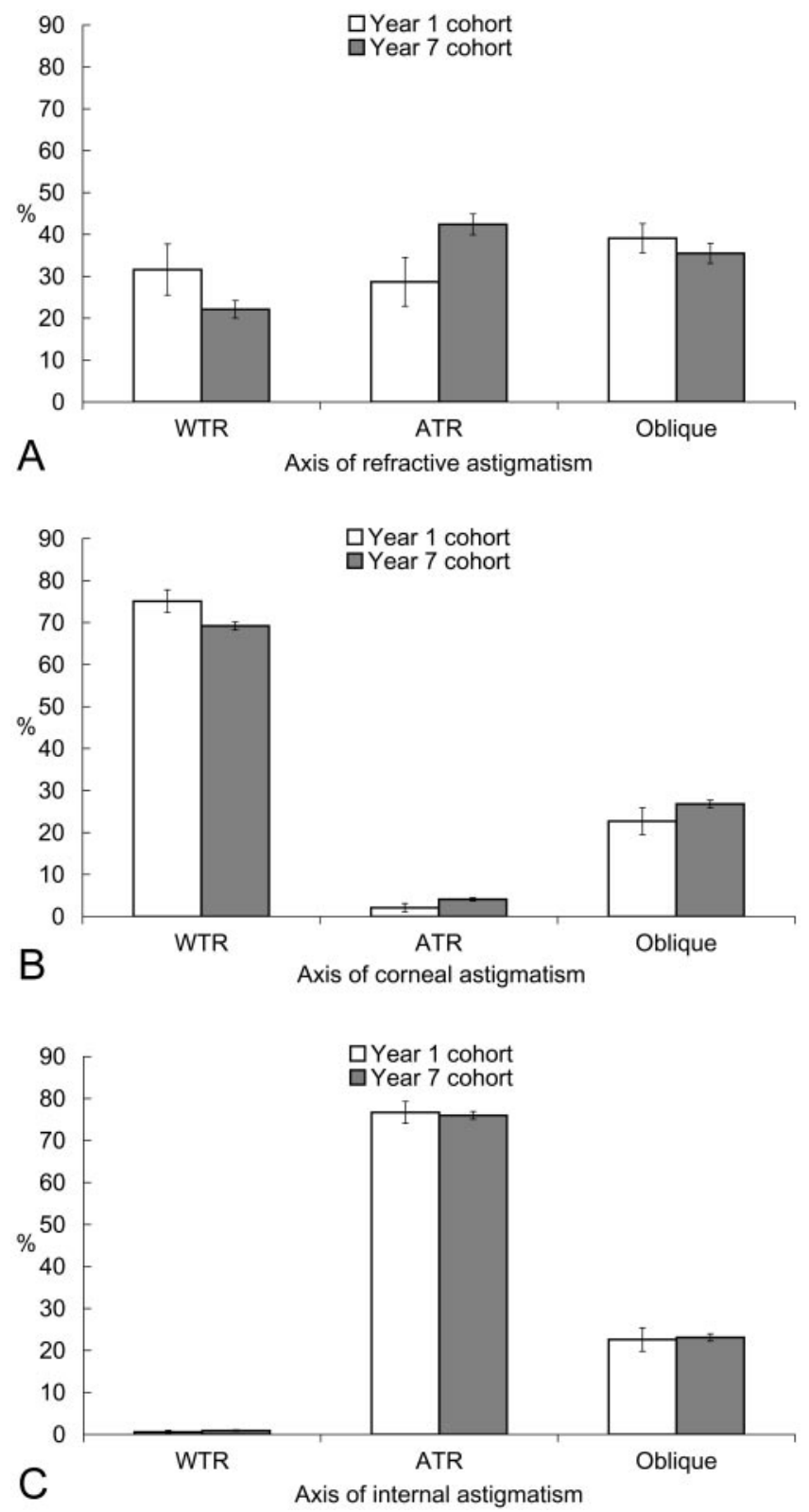

FIGURE 2. Comparative distributions in right eyes of WTR, ATR, and oblique axes of (A) refractive, (B) corneal, and (C) internal astigmatism of any magnitude between the cohorts of year $1^{9}(n=1740)$ and year $7(n=2353)$ students. Definitions: WTR $0 \pm 15^{\circ}$; ATR $90 \pm 15^{\circ}$; and oblique $16^{\circ}$ to $74^{\circ}$ and $106^{\circ}$ to $164^{\circ}$.

by a higher slope to this relationship; the slope for ATR and WTR astigmatism was higher than that for oblique astigmatism, and so compensation of oblique astigmatism was more effective. The slope was also higher, and compensation was thus less effective, in children with myopic or hyperopic refractions than in those who were emmetropic (Table 4). This finding is consistent with the higher prevalence of astigmatism in these refractive categories (Table 5). ${ }^{13-15}$

The relationship between refractive and corneal astigmatism has been described as Javal's rule by other research$\mathrm{ers}^{8,27-33}$ seeking to estimate refractive astigmatism from measured corneal astigmatism. Javal's rule is defined by the equation, refractive astigmatism $=a \times$ corneal astigmatism $0.5 \times 90^{\circ}$, where $a$ is a constant (originally 1.25 ) and $-0.5 \times$ $90^{\circ}$ represents a 0.5 -D ATR astigmatism. ${ }^{32}$ Conceptually, our results agree with Javal's rule, but detailed comparison is not appropriate, because we used a vector-based method of analysis, which took into account the exact astigmatic axis, whereas Javal's rule used a conventional classification system.

Studies of Javal's rule did not explore the role of compensation of corneal astigmatism by internal astigmatism in the development and progression of refractive astigmatism. A greater understanding of this process could help to explain observed effects of spherical errors, gender, ethnicity, and potentially other risk factors on the prevalence of astigmatism. Grosvenor and Ratnakaram ${ }^{32}$ suggested that the relationship between refractive and corneal astigmatism was affected by myopia, although the comparison groups in their study were not well characterized. Dobson et al. ${ }^{8}$ and Tong et al. ${ }^{28}$ used vector analysis but also did not examine subgroup differences. We found that compensation of astigmatism was affected by spherical (equivalent) errors, but not by gender or ethnicity, despite significant gender and ethnic differences in the magnitude and axis of corneal and internal astigmatism. These findings suggest that differences in the prevalence of refractive astigmatism between different populations are more likely to be associated with differences in the prevalence of spherical errors than with ethnicity per se.

\section{Developmental Perspective}

In previous studies, investigators have consistently found that there is a rapid decline in refractive astigmatism in the first 2 years of life, ${ }^{34-38}$ followed by slower changes occurring between ages 2 and 6 years. ${ }^{39}$ Our study found a slightly higher prevalence of refractive astigmatism in 12-year-old $(6.7 \%, \mathrm{CI}$, $5.0-8.4)$ than in 6-year-old children $\left(4.8 \%\right.$, CI, 3.8-6.1), ${ }^{9}$ although the confidence intervals overlapped widely, and the distribution of refractive astigmatism was similar between the two cross-sectional samples (Fig. 1A). These results suggest that refractive astigmatism is quite stable between the ages of 6 and 12 years. This conclusion is supported by two further findings. First, there was marked overlap in the confidence intervals of the prevalence of refractive astigmatism within the different categories of spherical equivalent refraction (Fig. 3A), except for the higher prevalence of refractive astigmatism among the older children in the moderate hyperopia category, which could be expected from a slight shift of the axis of corneal astigmatism from WTR to ATR (Fig. 2B). Second, prevalence rates of refractive, corneal, and internal astigmatism among the different ethnic groups were similar between the two cohorts, with widely overlapping CIs. Exceptions included the slightly higher prevalence of refractive astigmatism in the older children of European white background (5.6\%, CI, 4.66.7 vs. $3.6 \%, \mathrm{CI}, 2.8-4.7)$, and the lower prevalence of corneal astigmatism in the older children of South Asian background (26.4\%, CI, 18.0 - 34.7 vs. $48.1 \%$, CI, 34.9 - 66.4).

Findings in other studies, however, lead to inconsistent conclusions concerning later developmental changes in refractive astigmatism. Anstice ${ }^{40}$ reported a significant decrease in refractive astigmatism up to age 14 years, although the results were not adjusted for potential confounders such as the prevalence of myopia or hyperopia. In contrast, two studies of American children, the Berkeley Infant Biometry Study (BIBS) $)^{37}$ and the Collaborative Longitudinal Evaluation of Ethnicity and Refractive Error (CLEERE) study, ${ }^{5}$ reported prevalence rates of refractive astigmatism of $5.3 \%$ in 9 -month-old infants $^{37}$ and $28.4 \%$ in 5 - to 17 -year-old children. ${ }^{5}$ These differences are likely to be because refractive error was measured by retinoscopy in the BIBS and an autorefractor (R-1; Canon) in the CLEERE study. The children in the CLEERE study were also from several different ethnic backgrounds.

The rapid reduction in refractive astigmatism in infancy and early childhood is accompanied by dynamic compensatory 
Table 3. Distribution of Different Types of Axis of Astigmatism ( $\geq 1.0$ D) in Right Eyes with Stratification by Gender and Ethnic Background

\begin{tabular}{|c|c|c|c|c|c|c|c|}
\hline \multirow[b]{2}{*}{ Astigmatism Type } & \multirow[b]{2}{*}{$n(\%)$} & \multicolumn{2}{|c|}{ WTR } & \multicolumn{2}{|l|}{ ATR } & \multicolumn{2}{|c|}{ Oblique } \\
\hline & & $\%(95 \%$ CI $)$ & $\boldsymbol{P}^{*}$ & $\%(95 \% \mathrm{CI})$ & $\boldsymbol{P}^{*}$ & $\%(95 \%$ CI $)$ & $P^{*}$ \\
\hline \multicolumn{8}{|l|}{ Refractive } \\
\hline All & $156(100)$ & $40.4(32.6-48.2)$ & & $43.6(35.7-51.5)$ & & $16.0(10.2-21.8)$ & \\
\hline Boys & $78(50.0)$ & $35.9(25.1-46.7)$ & Referent & $44.9(33.7-56.0)$ & Referent & $19.2(10.4-28.1)$ & Referent \\
\hline Girls & $78(50.0)$ & $44.9(33.7-56.0)$ & 0.3 & $42.3(31.2-53.4)$ & 0.9 & $12.8(5.3-20.3)$ & 0.3 \\
\hline European white & $79(51.0)$ & $12.7(5.2-20.1)$ & Referent & $70.9(60.8-81.0)$ & Referent & $16.5(8.2-24.7)$ & Referent \\
\hline East Asian & $39(25.2)$ & $79.5(66.7-92.3)$ & $<0.0001$ & $5.1(0.0-12.1)$ & $<0.0001$ & $15.4(3.9-26.8)$ & 0.9 \\
\hline Middle Eastern & $11(7.1)$ & $54.5(24.8-84.3)$ & 0.0007 & $27.3(0.0-41.2)$ & 0.0009 & $18.2(0.0-41.2)$ & 0.8 \\
\hline South Asian $†$ & $15(9.7)$ & $73.3(50.7-96.0)$ & $<0.0001$ & $6.7(0.0-19.4)$ & 0.002 & $20.0(0.0-40.5)$ & 0.7 \\
\hline \multicolumn{8}{|l|}{ Corneal } \\
\hline All & $617(100)$ & $88.8(86.3-91.3)$ & & $1.3(0.3-2.0)$ & & $10.0(7.7-12.4)$ & \\
\hline Boys & $263(42.6)$ & $86.3(82.1-90.5)$ & Referent & $1.5(0.0-3.0)$ & Referent & $12.2(8.2-16.1)$ & Referent \\
\hline Girls & $354(57.4)$ & $90.7(87.6-93.7)$ & 0.2 & $0.8(0.0-1.8)$ & 0.4 & $8.5(5.6-11.4)$ & 0.1 \\
\hline European white & $265(43.1)$ & $87.5(83.6-91.5)$ & Referent & $1.5(0.0-3.0)$ & Referent & $10.9(7.2-14.7)$ & Referent \\
\hline East Asian & $175(28.5)$ & $90.9(86.6-95.1)$ & 0.2 & $0.6(0.0-1.7)$ & $\neq$ & $8.6(4.4-12.7)$ & 0.4 \\
\hline Middle Eastern & $35(5.7)$ & $91.4(82.1-100.0)$ & 0.5 & NA & - & $8.6(0.0-17.9)$ & 0.6 \\
\hline South Asian† & $34(5.5)$ & $91.2(81.6-100.0)$ & 0.4 & NA & - & $8.8(0.0-18.4)$ & 0.6 \\
\hline \multicolumn{8}{|l|}{ Internal } \\
\hline All & $612(100)$ & NA & - & $90.2(87.8-92.6)$ & & $9.8(7.4-12.2)$ & \\
\hline Boys & $273(44.6)$ & NA & Referent & $86.8(82.8-90.8)$ & Referent & $13.2(9.2-17.2)$ & Referent \\
\hline Girls & $339(55.4)$ & NA & - & $92.9(90.2-95.7)$ & 0.02 & $7.1(4.3-9.8)$ & 0.02 \\
\hline European white & $379(62.0)$ & NA & Referent & $90.5(87.5-93.5)$ & Referent & $9.5(6.5-12.5)$ & Referent \\
\hline East Asian & $100(16.4)$ & NA & - & $91.0(85.4-96.6)$ & 0.7 & $9.0(3.4-14.6)$ & 0.7 \\
\hline Middle Eastern & $27(4.4)$ & NA & - & $85.2(71.7-98.6)$ & $0.3 \Omega$ & $14.8(1.4-28.3)$ & 0.30 \\
\hline South Asian $\dagger$ & $17(2.8)$ & NA & - & $94.1(82.9-100.0)$ & 0.5 & $5.9(0.0-17.1)$ & 0.5 \\
\hline
\end{tabular}

NA, there were no children in these categories.

* Adjusted for cluster sampling. Unless indicated, statistical significances were unchanged after adjustment for age, gender, ethnic background, socioeconomic status, parental education, spherical equivalent, and cluster sampling.

† Comprised children of Indian, Pakistani, and Sri Lankan backgrounds.

‡ Samples were too small to perform these analyses.

$\S P=0.06$ after adjustment for age, gender, socioeconomic status, parental education, spherical equivalent, and cluster sampling.

changes in corneal and internal astigmatism. Mutti et al. ${ }^{37}$ found in the BIBS, which examined 302 American infants, that corneal astigmatism decreased rapidly in the first 9 months of life, in parallel with a narrowing distribution of spherical equivalent refraction, and then remained stable up to age 3 years. This was also accompanied by a rapid increase in lenticular ATR astigmatism between the ages of 3 and 18 months, after which changes were statistically nonsignificant. Our data build on these findings, because the apparent stability of astigmatism between our 6- and 12-year-old cohorts was also seen in similar distribution curves (Figs. 1B-1C) and prevalence rates of corneal $(27.7 \%$, CI, 23.8-32.3, 6-year-old; $26.6 \%$, CI, 22.1-31.1, 12-year-old) and internal (21.1\%, CI, 19.0-23.5, 6-year-old; 26.5\%, CI, 22.9-30.0, 12-year-old) astigmatism. The relative stability of these components between the ages of 6 and 12 years is further supported by the marked overlap in the CIs for the prevalence of both components when compared by spherical equivalent categories. The lack of change of corneal astigmatism is also consistent with findings by Kame et al. ${ }^{41}$ The data in Mutti et al. ${ }^{37}$ also suggest that during the process of compensation of astigmatism, changes in both corneal and internal astigmatism occur. Our data suggest that when refractive astigmatism is stable, both corneal and internal astigmatism do not change.

Figure 2 shows slight shifts in axis from WTR to ATR refractive astigmatism and from WTR to oblique corneal astigmatism, between the 6- and 12-year-old cohorts. The axis of internal astigmatism was not different between the two cohorts. The significance of the difference in axis is not clear, as it could be due to the arbitrary definition of axis of astigmatism. For example, axes of $74^{\circ}$ or $76^{\circ}$ would be categorized as oblique or WTR, respectively, although a difference of $2^{\circ}$ could easily be caused by measurement error.

\section{Gender Differences in Astigmatism}

Findings in previous studies on gender differences in astigmatism have been inconsistent. Several large population-based studies reported slightly higher prevalence rates of refractive astigmatism in girls than in boys, ${ }^{2,17,18,21}$ although several other studies reported no gender differences. ${ }^{3,19,24,39}$ In our study, despite the significantly greater corneal and internal astigmatism in the girls, the distribution of axes between the boys and girls were generally similar, and compensation of astigmatism resulted in similar levels and axis of refractive astigmatism.

\section{Comparisons with Other Populations}

In comparing the prevalence of refractive astigmatism between different populations, consideration should be given to population differences in age, spherical equivalent refractive error, corneal and internal astigmatism, sampling, instrumentation, definition, and possibly differences in other as yet unknown factors (Table 5). Several previous population-based studies involved children in a wide age range, ${ }^{3-5,17,18,21-24}$ and so it is difficult to compare their overall prevalence rates. In two studies of 12- to 13-year-old children, Villarreal et al. ${ }^{16}$ reported prevalence rates of refractive astigmatism $\geq 1.5 \mathrm{D}$ of $9.5 \%$ in Mexican children $(n=1035)$ and $5.2 \%$ in Swedish children $(n$ $=1045){ }^{20}$ The prevalence of myopia ( $44 \%$ and $44.9 \%$, respectively) and hyperopia (6.0\% and $8.4 \%$, respectively) was similar between the two studies, and so the difference in refractive astigmatism may be explained by other factors such as ethnicity or the ability to compensate for corneal astigmatism. Relatively high prevalence rates were reported for children in China (Guangzhou), ${ }^{3}$ Taiwan, ${ }^{4}$ Singapore,${ }^{19}$ Chile, ${ }^{23}$ and American Sioux Indian children. ${ }^{25}$ Comparatively low prevalence 

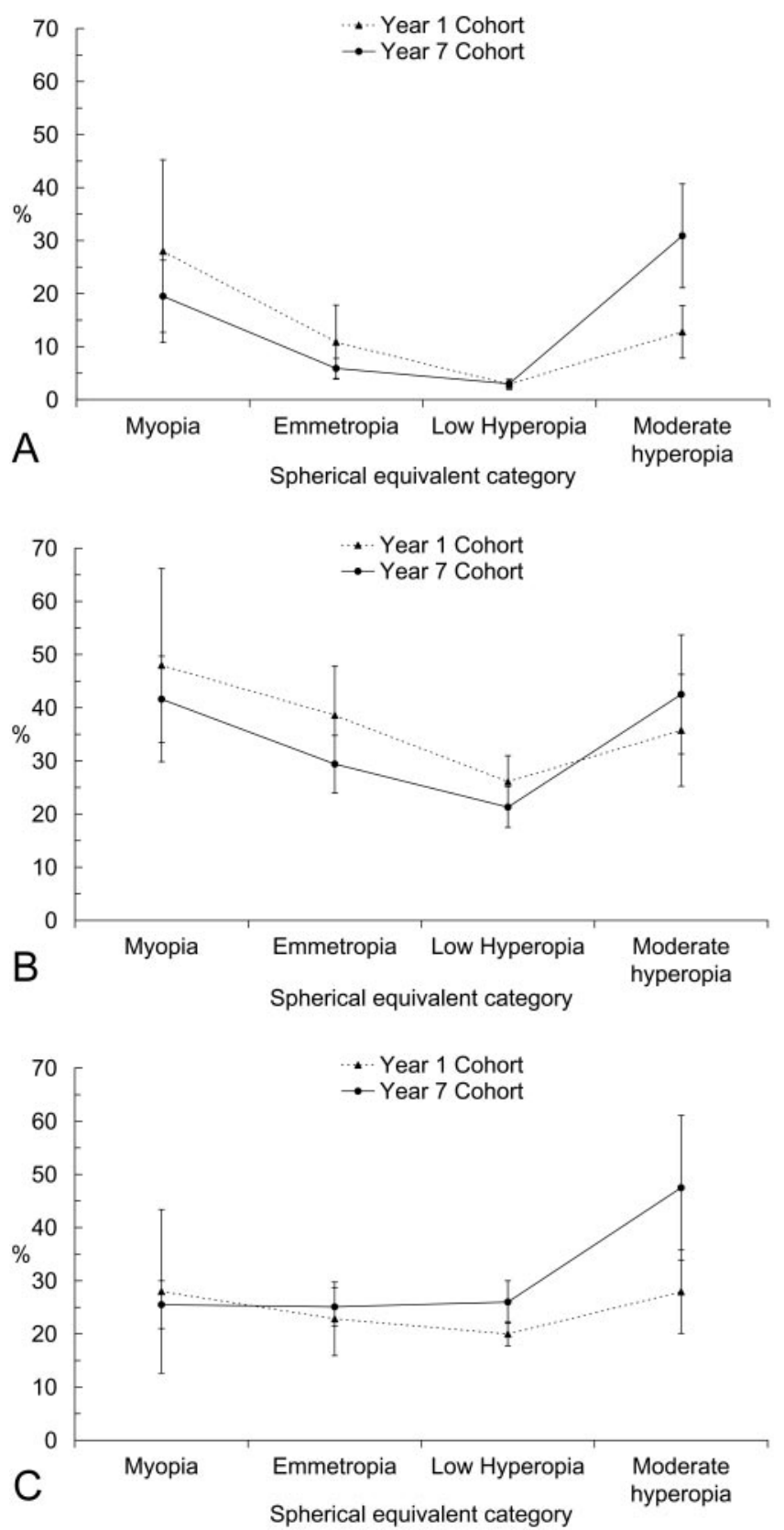

FigURE 3. Comparative distributions in right eyes of (A) refractive, (B) corneal, and (C) internal astigmatism by spherical equivalent (SEq) categories between the cohorts of year $1(n=1740)$ and year $7(n=$ 2353 ) students. Definitions: myopia (SEq $\leq-0.5 \mathrm{D} ; n=25$, year $1 ; n$ $=277$, year 7); emmetropia $(\mathrm{SEq}-0.49$ to $+0.50 \mathrm{D} ; n=129$, year 1 ; $n=590$, year 7 ); low hyperopia (SEq +0.51 to $+2.0 \mathrm{D} ; n=1390$, year $1 ; n=1388$, year 7$)$; moderate hyperopia $(\mathrm{SEq}>+2.0 \mathrm{D} ; n=180$, year $1 ; n=81$, year 7 ).

rates were found in children in Sweden, ${ }^{20} \mathrm{Nepal},{ }^{21}$ India,,${ }^{2,17}$ Finland, ${ }^{13}$ and Vanuatu. ${ }^{26}$ The particularly low prevalence $(0.3 \%)$ of astigmatism $\geq 1.0 \mathrm{D}$ in Melanesian children may reflect the low prevalence of myopia (2.9\%) and hyperopia $(0.3 \%$ with SEq $>1.0 \mathrm{D})$, but it could have been underestimated by the use of noncycloplegic retinoscopy. ${ }^{26}$ The very low prevalence of refractive astigmatism in Nepalese children is consistent with their low level of myopia. There are several other reported ethnic differences in refractive astigmatism, ${ }^{5,9,42-44}$ but whether these reflect genetic differences is not clear. Findings in some studies have suggested that astig- matism is dominantly inherited, ${ }^{45,46}$ whereas others have shown low heritability. ${ }^{47-49}$ Marked differences in the prevalence of astigmatism have been reported in children of Chinese origin in the RESC studies in Guangzhou ${ }^{3}$ and Shunyi ${ }^{22}$ (Table 5). Recently Saw et al. ${ }^{50}$ reported results that also suggest that environmental influences have a major impact on astigmatism. They studied 7- to 9-year-old children and compared three different ethnic groups (Chinese, Malay, and Indian) living in Singapore and Malaysia. They found that the prevalence of astigmatism (and myopia) in each ethnic group was greater in the children living in Singapore than in those in Malaysia. Thus, the relative contribution of genetic and environmental influences to ethnic and other differences in astigmatism requires further analysis.

Although many potential risk factors for astigmatism are still not well known, it is important to understand the mechanism by which they could affect refractive astigmatism. Children of European white background in our study had a significantly lower prevalence of refractive astigmatism than did children of East Asian, South Asian, and Middle Eastern backgrounds. Similar ethnic differences were also reported in our cohort of younger children. ${ }^{9}$ Our data show that the children of East Asian background had a higher level of refractive astigmatism than did those of European white background because they
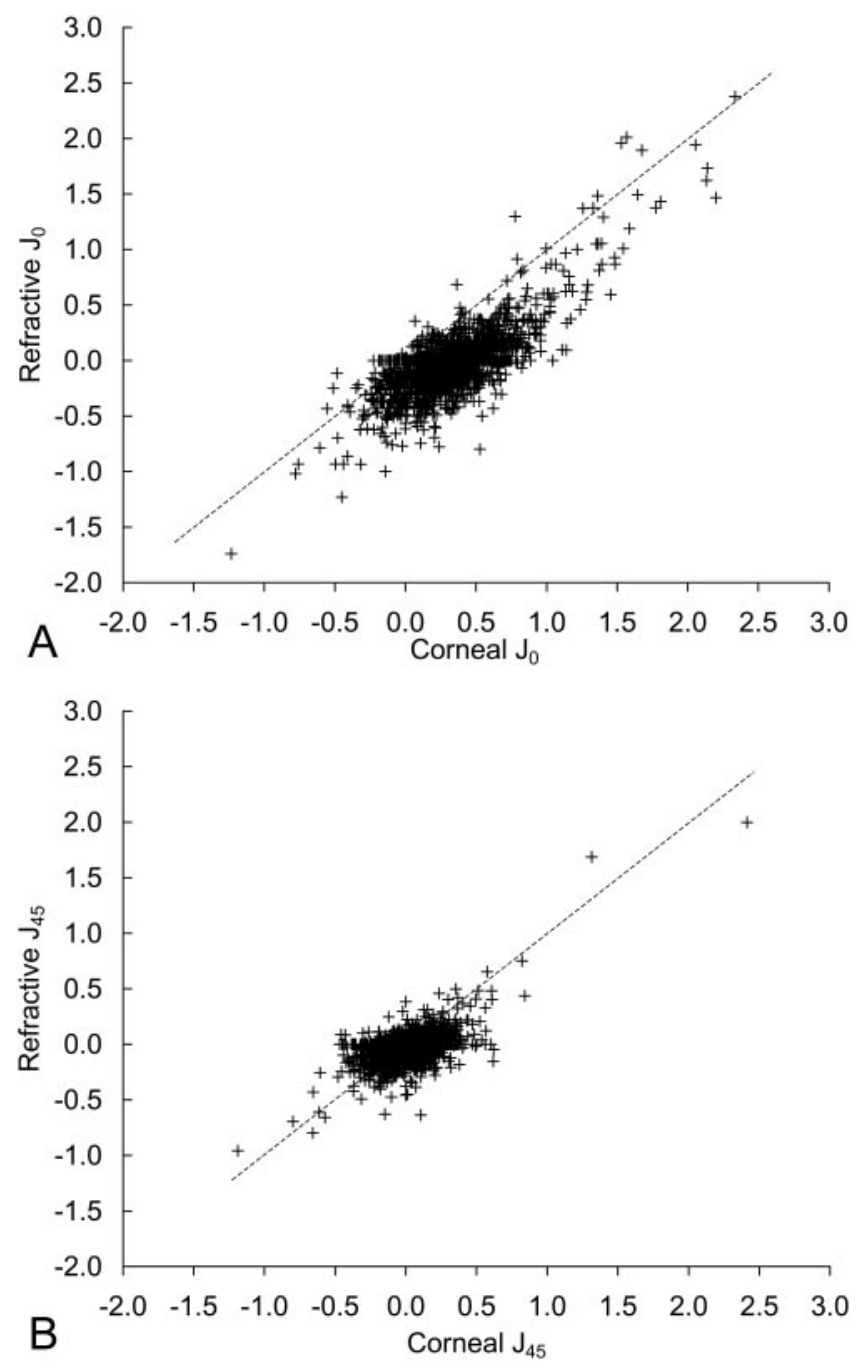

FiguRe 4. Scatter plots $(n=2347)$ of corneal versus refractive (A) $J_{0}$ vector and (B) $J_{45}$ vector in right eyes of year 7 students. Dashed line: a slope of 1 . 
TABLE 4. Effect of SEq Refraction on the Regression Slope of Refractive Versus Corneal Astigmatism Vectors in Right Eyes

\begin{tabular}{|c|c|c|c|c|}
\hline \multirow[b]{2}{*}{ Refractive Category (SEq) } & \multicolumn{2}{|c|}{$J_{0}$ Vector } & \multicolumn{2}{|c|}{$J_{45}$ Vector } \\
\hline & Slope $(95 \% \mathrm{CI})$ & $\boldsymbol{P}$ & Slope $(95 \%$ CI) & $\boldsymbol{P}$ \\
\hline Myopia $(\leq-0.5)$ & $0.80(0.71-0.89)$ & 0.0007 & $0.61(0.46-0.77)$ & 0.0002 \\
\hline Emmetropia $(-0.49$ to +0.5$)$ & $0.61(0.53-0.70)$ & Referent & $0.31(0.26-0.35)$ & Referent \\
\hline Low hyperopia $(0.51$ to +2.0$)$ & $0.43(0.37-0.50)$ & $<0.0001$ & $0.24(0.17-0.32)$ & 0.2 \\
\hline Moderate hyperopia $(>+2.0)$ & $1.05(0.92-1.17)$ & $<0.0001$ & $0.82(0.57-1.07)$ & 0.0003 \\
\hline
\end{tabular}

Probabilities were adjusted for gender, ethnic background, and cluster sampling.

had markedly greater levels of corneal astigmatism and similar levels of internal astigmatism. This pattern was also evident in the comparison between the children of Middle Eastern and European white background for astigmatism $\geq 1.5$ D. In contrast, the children of South Asian background had a higher level of refractive astigmatism than did those of European white background despite having similar levels of corneal astigmatism, because they had lower levels of internal astigmatism. Although our analysis of the relationship of corneal and refractive astigmatic vectors found no significant overall effect of ethnicity on the efficiency of astigmatic compensation, the stratified data suggest that the pattern of astigmatic compensation may be different between different ethnic groups. Further, it is likely that the factors associated with refractive astigmatism have variable effects on corneal and internal astigmatism. For example, eyelid pressure can induce WTR corneal astigmatism $^{51}$; and myopia is associated with greater increases in corneal than internal astigmatism, but hyperopia is associated with similar increases in these components of astigmatism (Fig. 3B, 3C).

Strengths of this study included the large sample, population-based design, detailed examination, use of cycloplegic refraction, and analysis of both magnitude and axis of astigmatism. It should be noted, though, that corneal astigmatism was calculated with an assumed refractive index, and internal astigmatism was also calculated. Inferences regarding longitudinal changes were made from two cross-sectional samples and should be confirmed in longitudinal studies.

TABLE 5. Prevalence of Astigmatism from Selected Studies that Included Children in the Age Range of Children in the Current Study

\begin{tabular}{|c|c|c|c|c|c|c|c|c|c|}
\hline \multirow[b]{2}{*}{ Author } & \multirow[b]{2}{*}{ Year } & \multirow[b]{2}{*}{ Country } & \multirow[b]{2}{*}{ Study Population } & \multirow[b]{2}{*}{$\boldsymbol{n}$} & \multirow[b]{2}{*}{$\begin{array}{l}\text { Age } \\
(y)\end{array}$} & \multirow[b]{2}{*}{$\begin{array}{l}\text { Refraction } \\
\text { Method }\end{array}$} & \multirow[b]{2}{*}{$\begin{array}{c}\text { Myopia* } \\
\text { Prevalence } \\
(\%)\end{array}$} & \multicolumn{2}{|c|}{ Astigmatism } \\
\hline & & & & & & & & $\begin{array}{l}\text { Definition } \\
\text { (D) }\end{array}$ & $\begin{array}{c}\text { Prevalence } \\
(\%)\end{array}$ \\
\hline Current study & & Australia & Urban, population-based & 2,353 & $12-13$ & $\mathrm{C}, \mathrm{A}$ & 12.8 & $\begin{array}{l}\geq 1.5 \\
\geq 1.0 \\
\geq 0.75\end{array}$ & $\begin{array}{r}2.6 \\
6.7 \\
13.6\end{array}$ \\
\hline Huynh et al. ${ }^{9}$ & 2006 & Australia & Urban, population-based & 1,765 & $6-7$ & $\mathrm{C}, \mathrm{A}$ & 1.4 & $\geq 1.0$ & 4.8 \\
\hline He et al. $^{3}$ & 2004 & China (Guangzhou) & Urban, population-based (RESC) & 4,364 & $5-15$ & $\mathrm{C}, \mathrm{A}$ & 38.1 & $\geq 0.75$ & 42.7 \\
\hline Shih et al. ${ }^{4}$ & 2004 & Taiwan & Population-based & 11,175 & $7-18$ & $\mathrm{C}, \mathrm{A}$ & $20 \dagger$ & $\geq 1.0$ & 18.4 \\
\hline Kleinstein et al. ${ }^{5}$ & 2003 & $\begin{array}{l}\text { Overall } \\
\text { African } \\
\text { American Asian } \\
\text { Hispanic white }\end{array}$ & Population-based & $\begin{array}{r}2,523 \\
534 \\
491 \\
463 \\
1,034\end{array}$ & $5-17$ & $\mathrm{C}, \mathrm{A}$ & $\begin{array}{r}10.5 \\
8.6 \\
19.8 \\
14.5 \\
5.2\end{array}$ & $\geq 1.0$ & $\begin{array}{l}28.4 \\
20.0 \\
33.6 \\
36.9 \\
26.4\end{array}$ \\
\hline Villarreal et al. ${ }^{16}$ & 2003 & Mexico & Urban school children & 1,035 & $12-13$ & $\mathrm{C}, \mathrm{A}$ & 44.0 & $\geq 1.5$ & 9.5 \\
\hline Dandona et al. ${ }^{17}$ & 2002 & India (Andra Pradesh) & Rural, population-based (RESC) & 4,074 & $7-15$ & $\mathrm{C}, \mathrm{A}$ & 4.1 & $\geq 0.75$ & 5.9 \\
\hline Murthy et al. ${ }^{18}$ & 2002 & India (New Delhi) & Urban, population-based (RESC) & 6,447 & $5-15$ & $\mathrm{C}, \mathrm{A}$ & 7.4 & $\geq 0.75$ & 9.8 \\
\hline Tong et al. ${ }^{19}$ & 2002 & Singapore & Children from 2 schools & 1,028 & $7-9$ & $\mathrm{C}, \mathrm{A}$ & 32 & $\geq 1.0$ & 19.2 \\
\hline Villarreal et al. ${ }^{20}$ & 2000 & Sweden & Urban, population-based & 1,045 & $12-13$ & $\mathrm{C}, \mathrm{R}$ & 44.9 & $\geq 1.5$ & 5.2 \\
\hline Pokharel et al. ${ }^{21}$ & 2000 & Nepal & Rural, population-based (RESC) & 5,067 & $5-15$ & $\mathrm{C}, \mathrm{A}$ & 0.3 & $\geq 0.75$ & 3.5 \\
\hline Zhao et al. ${ }^{22}$ & 2000 & China (Shunyi) & Rural, population-based (RESC) & 5,884 & $5-15$ & $\mathrm{C}, \mathrm{A}$ & 14.9 & $\geq 0.75$ & 9.5 \\
\hline Maul et al. ${ }^{23}$ & 2000 & Chile (La Florida) & Urban, population-based (RESC) & 5,303 & $5-15$ & $\mathrm{C}, \mathrm{A}$ & 5.8 & $\geq 0.75$ & 27.2 \\
\hline Dandona et al. ${ }^{2}$ & 1999 & India & $\begin{array}{l}\text { Urban, population-based } \\
\text { (Andra Pradesh Eye Study) }\end{array}$ & 663 & $\leq 15$ & $\mathrm{C}, \mathrm{R}$ & $4.4 \neq$ & $\geq 1.0$ & $3.8 \Omega$ \\
\hline Kalikivayi et al. ${ }^{24}$ & 1997 & India & Urban, population-based & 4,029 & $3-18$ & $\mathrm{C} \|, \mathrm{SR}$ & 8.6 & $\geq 0.5$ & $8.7 \pi$ \\
\hline Pensyl et al. ${ }^{25}$ & 1997 & United States & Sioux Indian clinic subjects & 174 & $0-19$ & $\mathrm{C}, \mathrm{A}$ & 18.8 & $\geq 1.0$ & 44.2 \\
\hline Parssinen $^{13}$ & 1991 & Finland & $\begin{array}{l}\text { Myopic school children with } \\
\leq 2 \text { D of astigmatism }\end{array}$ & 238 & $10.9 \#$ & $\mathrm{C}, \mathrm{SR}$ & $\begin{array}{c}-0.25 \\
\text { to }-3^{* * *}\end{array}$ & $\geq 1.0$ & 3.8 \\
\hline Garner et al. ${ }^{26}$ & 1988 & Vanuatu & $\begin{array}{l}\text { Melanesian children from } 4 \\
\text { schools }\end{array}$ & 788 & $6-19$ & $\mathrm{NC}, \mathrm{R}$ & 2.9 & $\geq 1.0$ & 0.3 \\
\hline
\end{tabular}

$n$, number of children in age group; C, cycloplegic; NC, noncycloplegic; A, autorefraction; R, retinoscopy; SR, subjective refraction; RESC, Refractive Error Study in Children.

* Spherical equivalent $(\mathrm{SE}) \leq-0.5 \mathrm{D}$, unless indicated.

† Estimated for 12-13 year old children.

¥ Myopia defined as $\mathrm{SE}<-0.5 \mathrm{D}$.

$₫$ Astigmatism in the worse eye.

$\|$ Cycloplegia performed only in hyperopic children.

II Prevalence in children $<10$ years old.

\# Mean age.

** Range of SEq. 
In summary, we have reported in this cross-sectional survey of older Australian children a relatively low prevalence of refractive astigmatism that varied little between different ethnic groups. The prevalence rates of all components of astigmatism were minimally different, with values previously reported for our cohort of 6-year-old children, suggesting that astigmatism is relatively stable in children between the ages of 6 and 12 years. Compensation between corneal and internal astigmatism to minimize refractive astigmatism appears to be more effective along the oblique meridian. The pattern of compensation appears to be different in different ethnic groups; and although myopic and hyperopic refractive errors most strongly affected the capacity for astigmatic compensation, these refractive errors had variable effects on corneal and internal astigmatism. Future research should be undertaken to examine the finding of the stability of astigmatism using longitudinal samples and to explore further factors that may reduce the efficiency of astigmatic compensation.

\section{References}

1. Robaei D, Rose K, Ojaimi E, et al. Visual acuity and the causes of visual loss in a population-based sample of 6-year-old Australian children. Opbthalmology. 2005;112:1275-1282.

2. Dandona R, Dandona L, Naduvilath TJ, et al. Refractive errors in an urban population in Southern India: the Andhra Pradesh Eye Disease Study. Invest Ophthalmol Vis Sci. 1999;40:2810-2818.

3. He M, Zeng J, Liu Y, et al. Refractive error and visual impairment in urban children in southern China. Invest Opbthalmol Vis Sci. 2004;45:793-799.

4. Shih YF, Hsiao CK, Tung YL, et al. The prevalence of astigmatism in Taiwan schoolchildren. Optom Vis Sci. 2004;81:94-98.

5. Kleinstein RN, Jones LA, Hullett $S$, et al. Refractive error and ethnicity in children. Arch Opbthalmol. 2003;121:1141-1147.

6. McKendrick AM, Brennan NA. Distribution of astigmatism in the adult population. J Opt Soc Am A. 1996;13:206-214.

7. Dunne MC, Elawad ME, Barnes DA. A study of the axis of orientation of residual astigmatism. Acta Opbthalmol (Copenb). 1994;72: 483-489.

8. Dobson V, Miller JM, Harvey EM. Corneal and refractive astigmatism in a sample of 3- to 5-year-old children with a high prevalence of astigmatism. Optom Vis Sci. 1999;76:855-860.

9. Huynh SC, Kifley A, Rose KA, et al. Astigmatism and its components in 6-year-old children. Invest Ophthalmol Vis Sci. 2006;47: 55-64.

10. Ojaimi E, Rose KA, Smith W, et al. Methods for a population-based study of myopia and other eye conditions in school children: the Sydney Myopia Study. Ophthalmic Epidemiol. 2005;12:59-69.

11. Thibos LN, Wheeler W, Horner D. Power vectors: an application of Fourier analysis to the description and statistical analysis of refractive error. Optom Vis Sci. 1997;74:367-375.

12. Munoz-Escriva L, Furlan WD. Statistical analysis when dealing with astigmatism: assessment of different spherocylindrical notations. Ophthalmic Epidemiol. 2001;8:27-37.

13. Parssinen O. Astigmatism and school myopia. Acta Opbthalmol (Copenb). 1991;69:786-790.

14. Gwiazda J, Grice K, Held R, et al. Astigmatism and the development of myopia in children. Vision Res. 2000;40:1019-1026.

15. Fulton AB, Hansen RM, Petersen RA. The relation of myopia and astigmatism in developing eyes. Opbthalmology. 1982;89:298302 .

16. Villarreal GM, Ohlsson J, Cavazos H, et al. Prevalence of myopia among 12- to 13-year-old schoolchildren in northern Mexico. OPtom Vis Sci. 2003;80:369-373.

17. Dandona R, Dandona L, Srinivas M, et al. Refractive error in children in a rural population in India. Invest Opbthalmol Vis Sci. 2002; 43:615-622.

18. Murthy GV, Gupta SK, Ellwein LB, et al. Refractive error in children in an urban population in New Delhi. Invest Opbthalmol Vis Sci. 2002; 43:623-631.
19. Tong L, Saw SM, Carkeet A, et al. Prevalence rates and epidemiological risk factors for astigmatism in Singapore school children. Optom Vis Sci. 2002;79:606-613.

20. Villarreal MG, Ohlsson J, Abrahamsson M, et al. Myopisation: the refractive tendency in teenagers: prevalence of myopia among young teenagers in Sweden. Acta Opbthalmol Scand. 2000;78: 177-181.

21. Pokharel GP, Negrel AD, Munoz SR, Ellwein LB. Refractive Error Study in Children: results from Mechi Zone, Nepal. Am J Opbthalmol. 2000;129:436-444.

22. Zhao J, Pan X, Sui R, et al. Refractive Error Study in Children: results from Shunyi District, China. Am J Opbthalmol. 2000;129: 427-435.

23. Maul E, Barroso S, Munoz SR, et al. Refractive Error Study in Children: results from La Florida, Chile. Am J Ophthalmol. 2000; 129:445- 454 .

24. Kalikivayi V, Naduvilath TJ, Bansal AK, Dandona L. Visual impairment in school children in southern India (published correction Indian J Opbthalmol. 1997;45:168). Indian J Opbthalmol. 1997; 45:129-134.

25. Pensyl CD, Harrison RA, Simpson P, Waterbor JW. Distribution of astigmatism among Sioux Indians in South Dakota. J Am Optom Assoc. 1997;68:425-431.

26. Garner LF, Kinnear RF, McKellar M, et al. Refraction and its components in Melanesian schoolchildren in Vanuatu. Am J Optom Pbysiol Opt. 1988;65:182-189.

27. Kelly JE, Mihashi T, Howland HC. Compensation of corneal horizontal/vertical astigmatism, lateral coma, and spherical aberration by internal optics of the eye. J Vis. 2004;4:262-271.

28. Tong L, Carkeet A, Saw SM, Tan DT. Corneal and refractive error astigmatism in Singaporean schoolchildren: a vector-based Javal's rule. Optom Vis Sci. 2001;78:881-887.

29. Baldwin WR, Mills D. A longitudinal study of corneal astigmatism and total astigmatism. Am J Optom Pbysiol Opt. 1981;58: 206-211.

30. Keller PR, Collins MJ, Carney LG, et al. The relation between corneal and total astigmatism. Optom Vis Sci. 1996;73:86-91.

31. Elliott M, Callender MG, Elliott DB. Accuracy of Javal's rule in the determination of spectacle astigmatism. Optom Vis Sci. 1994;71: 23-26.

32. Grosvenor T, Ratnakaram R. Is the relation between keratometric astigmatism and refractive astigmatism linear? Optom Vis Sci. 1990;67:606-609.

33. Grosvenor T, Quintero S, Perrigin DM. Predicting refractive astigmatism: a suggested simplification of Javal's rule. Am J Optom Pbysiol Opt. 1988;65:292-297.

34. Atkinson J, Braddick O, French J. Infant astigmatism: its disappearance with age. Vision Res. 1980;20:891-893.

35. Gwiazda J, Scheiman M, Mohindra I, Held R. Astigmatism in children: changes in axis and amount from birth to six years. Invest Opbthalmol Vis Sci. 1984;25:88-92.

36. Dobson V, Fulton AB, Sebris SL. Cycloplegic refractions of infants and young children: the axis of astigmatism. Invest Opbthalmol Vis Sci. 1984;25:83-87.

37. Mutti DO, Mitchell GL, Jones LA, et al. Refractive astigmatism and the toricity of ocular components in human infants. Optom Vis Sci. 2004;81:753-761.

38. Abrahamsson M, Fabian G, Sjostrand J. Changes in astigmatism between the ages of 1 and 4 years: a longitudinal study. $B r J$ Ophthalmol. 1988;72:145-149.

39. Fan DS, Rao SK, Cheung EY, et al. Astigmatism in Chinese preschool children: prevalence, change, and effect on refractive development. Br J Ophthalmol. 2004;88:938-941.

40. Anstice J. Astigmatism: its components and their changes with age. Am J Optom Arch Am Acad Optom. 1971;48:1001-1006.

41. Kame RT, Jue TS, Shigekuni DM. A longitudinal study of corneal astigmatism changes in Asian eyes. J Am Optom Assoc. 1993;64: 215-219.

42. Garber JM. High corneal astigmatism in Navajo school children and its effect on classroom performance. J Am Optom Assoc. 1981;52: 583-586. 
43. Garber JM, Hughes J. High corneal astigmatism in the adult Navajo population. J Am Optom Assoc. 1983;54:815-818.

44. Kragha IK. Corneal power and astigmatism. Ann Ophthalmol. 1986;18:35-37.

45. Clementi M, Angi M, Forabosco P, et al. Inheritance of astigmatism: evidence for a major autosomal dominant locus. Am J Hum Genet 1998;63:825-830.

46. Hammond CJ, Snieder H, Gilbert CE, Spector TD. Genes and environment in refractive error: the twin eye study. Invest $O p b$ thalmol Vis Sci. 2001;42:1232-1236.

47. Mash AJ, Hegmann JP, Spivey BE. Genetic analysis of indices of corneal power and corneal astigmatism in human populations with varying incidences of strabismus. Invest Ophthalmol. 1975; $14: 826-832$.

48. Teikari J, O’Donnell JJ, Kaprio J, Koskenvuo M. Genetic and environmental effects on oculometric traits. Optom Vis Sci. 1989;66: 594-599.

49. Teikari JM, O’Donnell JJ. Astigmatism in 72 twin pairs. Cornea. 1989;8:263-266.

50. Saw SM, Goh PP, Cheng A, et al. Ethnicity-specific prevalence rates of refractive errors vary in Asian children in neighboring Malaysia and Singapore. Br J Opbthalmol. 2006;90:1230-1235.

51. Wilson G, Bell C, Chotai S. The effect of lifting the lids on corneal astigmatism. Am J Optom Physiol Opt. 1982;59:670-674. 